\title{
Digital and physical models in graphic representation teaching: a didactic experience
}

\section{SIGRADI2018 TECHNOPOLITICAS \\ xxii congresso da sociedade iberoamericana de gráfica digital 22th conference of the iberoamerican society of digital graphics $07|08| 09 \mid$ novembro|2018 iau usp | são carlos | sp br}

\author{
Luciana Sandrini Rocha \\ IFSul | Brazil | lusandrinirocha@gmail.com \\ Taís Feijó Viana \\ IFSul | Brazil | taisfviana@gmail.com \\ Tatiane Brisolara Nogueira \\ IFSul | Brazil | tatiane.b.nogueira@gmail.com
}

\begin{abstract}
Drawing is a language that involves processes of coding and decoding images and must be dominated by professionals who act on the space. In order to contribute to the discussions about graphic representation teaching, this study aims to analyze students' perceptions about two didactic experiences of orthographic views representation: through interaction with physical model and digital model. It seeks to understand which experience is evaluated by the students as the most significant. Another issue of interest to the authors is to understand how much their interaction with the digital object can be considered 'concrete', since they are digital natives.
\end{abstract}

Keywords: drawing; spatial visualization; perception; physical model x digital model.

\section{INTRODUÇÃO}

O presente estudo adota como premissa que o desenho é meio de comunicação, investigação, criação e reflexão. 0 exercício do desenho constitui uma atividade "mental e motora" (Florio, 2013, p. 51) capaz de desenvolver o raciocínio visuoespacial, cuja importância é fundamental para os profissionais que atuam sobre o espaço, tais como arquitetos, engenheiros e técnicos de diversas áreas.

O desenho, assim entendido, é uma linguagem bem desenvolvida na criança, mas tende a diminuir consideravelmente ao longo de seu processo de desenvolvimento cognitivo. As razões para tal podem ser inúmeras, mas admite-se que isso ocorra em parte pela conquista de novas habilidades de comunicação, como a linguagem escrita. $O$ caráter investigativo também diminui conforme a criança cresce e as questões sociais e de grupo adquirem maior importância. Nesse caso, mesmo as que mantém o hábito de desenhar acabam dando preferência aos modelos preexistentes, como os mangás (Castral, 2014).

A importância do desenho vem diminuindo também no âmbito escolar. Entende-se que isto se dá, em parte, por alterações na legislação que estrutura o ensino básico. Kopke (2009) relata que a partir da $2^{\underline{a}}$ Lei de Diretrizes e Bases da Educação Nacional a Educação Artística passou a ser disciplina obrigatória e o desenho ficou compreendido pelos estudos de artes e matemática. No entendimento da autora, esta lei representou uma mudança importante no ensino de desenho, pois a partir desta alteração, na prática, valorizou-se mais a criatividade e o desenho livre. Observa-se que esta alteração teve como consequência a diminuição de associação do desenho a um raciocínio lógicomatemático.

Por outra parte, os Parâmetros Curriculares Nacionais, que complementam a LDB/96, apontam para a importância do desenvolvimento da visualização espacial e o relacionam ao ensino de matemática. Entretanto, como observou Bueno (2015), raramente um estudante terá solucionado um problema de geometria por meio de representação gráfica, pois os cursos que formam os professores de Matemática também vêm abdicando do uso da representação gráfica para a solução de problemas de geometria.

Assim, ao associar o desenvolvimento da visualização espacial ao ensino da matemática a situação se agrava, pois o professor não encontra em sua própria formação o respaldo para promover o desenvolvimento desta habilidade. Isso se configura como problema porque, além da complexidade própria do desenvolvimento da visualização espacial, dos processos de codificação e decodificação de representações gráficas de objetos, se soma o ineditismo dos conteúdos de desenho e uma carência de conceitos básicos para os estudantes que ingressam na formação de nível superior e pós-médio no Brasil. Isso graças "à pouca importância ou inexistência do ensino de desenho em suas diferentes modalidades, especialmente geometria, perspectiva e geometria descritiva" (Rheingantz, 2016, p. 96).

Além disso, o crescimento do acesso aos meios digitais tende a aumentar o desinteresse pelo desenho por parte dos estudantes de hoje, que são "nativos digitais" 
(Prenski, 2001, p. 1). Sua forma de pensar (e aprender) está mudando com a internet (Carr, 2011, p. 16). Eles se apropriam muito rapidamente das tecnologias gráficodigitais porque são acostumados aos jogos eletrônicos, onde recebem informações rapidamente e aleatoriamente, analisam gráficos antes de textos, são habituados à interação em rede e apreciam gratificações instantâneas (Prenski, 2001, p. 2). Por isso tais tecnologias são tão estimulantes para essa geração, que tende a perder o interesse por atividades de outras naturezas.

Entretanto tem-se a compreensão de que, por si só, as tecnologias gráfico-digitais não promovem o desenvolvimento do raciocínio visuoespacial, pois também requerem a apropriação desse raciocínio para compreender e/ou solucionar questões relacionadas à geometria e aos sistemas de representação. Os programas de desenho paramétrico que funcionam através de algoritmos matemáticos, por exemplo, exigem níveis muito abstratos e complexos de raciocínio, e consequentemente são de difícil compreensão para os estudantes.

É importante também refletir a respeito do papel do professor de representação gráfica inserido nesse contexto. Em geral os professores advindos de cursos de bacharelado, como arquitetos e engenheiros, não possuem formação pedagógica, dispondo de pouco conhecimento didático para auxiliar os estudantes, o que agrava o problema. Dessa forma, as autoras investem num estudo que busca apoiar-se em teorias de desenvolvimento cognitivo, numa tentativa de resgatar conhecimentos que possam melhor auxiliar o desenho didático de atividades futuras.

Além disso, como se explicitou acima, a tecnologia digital seduz os usuários dos programas gráficos, em especial os nativos digitais. O professor precisa ter uma visão sistêmica dos conceitos com os quais vai trabalhar, utilizando a tecnologia de modo consciente, apropriandose dela e utilizando-a quando esta for a melhor opção para atingir seus objetivos pedagógicos. Qualquer imagem produzida deve ser carregada de significados, assim como o são os desenhos infantis e os croquis a mão dos arquitetos, que conectam mão e cérebro para exprimir ou explorar ideias. Flusser (1998) define as imagens como "superfícies que pretendem representar algo [...]. As imagens são, portanto, resultado do esforço de se abstrair duas das quatro dimensões espáciotemporais, para que se conservem apenas as dimensões do plano. Devem a sua origem à capacidade de abstracção específica a que podemos chamar imaginação [...]. Noutros termos, a imaginação é a capacidade de codificar os fenómenos de quatro dimensões em símbolos planos e descodificar as mensagens assim codificadas. Imaginação é a capacidade de fazer e decifrar imagens" (p. 23).

O desenho é, portanto, a representação de ideias através de um processo de codificação e decodificação: é uma linguagem. A imaginação se relaciona, de certa forma, ao domínio sobre essa linguagem.

Não se pode ignorar a importância dos programas gráficos para os projetos de arquitetura, no entanto
Sennet (2015) chama a atenção para o fato de que a má utilização desses programas pode levar à concepção de edifícios desconectados entre a simulação e a realidade, ao contrário do desenho a mão, onde "o tátil, o relacional e o incompleto são experiências físicas que ocorrem no ato de desenhar" (p. 55). Belas imagens renderizadas muitas vezes escondem projetos pobres em conteúdo. O domínio sobre os software digitais não garante a formação de bons projetistas, mas certamente vai auxiliar na instrumentalização de seus processos criativos. O software deve ser compreendido como ferramenta capaz de potencializar processos criativos, o que ocorrerá mais efetivamente se 0 projetista tiver desenvolvido o raciocínio visuoespacial, necessário à fluência da linguagem adotada na comunicação de suas ideias: o desenho. Flusser (1998) analisa as relações que o homem estabelece com os aparelhos:

"Sempre se supôs que os instrumentos são modelos do pensamento. O homem inventa-os, tendo por modelo o seu próprio corpo. Esquece-se depois do modelo, $<<$ aliena-se >> e vai tomar o instrumento como modelo do mundo, de si próprio e da sociedade" (p. 93).

A linguagem das imagens precisa ser decodificada pelos usuários dos programas gráficos, buscando suplantar a caixa negra a que se refere Flusser isto é, compreender como ocorre "o processo codificador que se passa no interior da caixa negra” (1998, p. 35),. O professor precisa auxiliar seus estudantes a dominarem a linguagem específica da representação gráfica, com seus signos e símbolos próprios. A habilidade de visualização espacial bem desenvolvida auxilia na compreensão do desenho a partir do raciocínio lógico-matemático, que é essencial aos profissionais que atuam sobre o espaço.

Assim, em ambientes educativos é importante que sejam estimuladas atividades apoiadas tanto em técnicas analógicas quanto digitais, pois cada qual, com suas particularidades, vai contribuir nos processos de ensinoaprendizagem. Os professores precisam conhecer as potencialidades das ferramentas de que dispõem, ou seja, saber como cada uma pode auxiliar na compreensão dos conceitos que serão trabalhados, respeitando ainda as peculiaridades de cada estudante (conhecimentos prévios, idade, etc.). Por exemplo, o desenho a mão é muito importante no processo de investigação formal, mesmo para os nativos digitais. Geometrias simples podem ser facilmente modeladas em software intuitivos como o SketchUp, mas geometrias complexas devem ser parametrizadas através de algoritmos em software específicos para tal, como Grasshopper e Dynamo, por exemplo. Já o desenvolvimento de projetos executivos é muito beneficiado pela utilização da tecnologia BIM, pela facilidade do trabalho em rede e pela associação de dados qualitativos aos objetos modelados. Assim, é necessário que 0 docente articule o conhecimento teórico-conceitual ao conhecimento das ferramentas analógicas e digitais disponíveis, para que todo o processo de ensino-aprendizagem seja mais efetivo.

A pesquisa, que está em andamento, se desenvolve em torno desta problemática. Tem como objetivo geral a produção de subsídios teóricos e científicos que auxiliem na instrumentalização dos processos de ensino- 
aprendizagem visando o desenvolvimento do raciocínio visuoespacial para a representação gráfica.

Nesta etapa da pesquisa se pretende compreender qual a percepção dos estudantes em relação a duas experiências de interação: (i) com um objeto virtual no espaço digital e (ii) com uma maquete física. Busca-se a compreensão sobre qual delas é avaliada por eles como sendo a mais significativa, fazendo ainda um paralelo com a correção das atividades para verificar se a percepção deles se espelha nos produtos dessas interações. Outra questão de interesse das autoras é compreender o quão 'concreta' pode ser considerada a interação deles com o objeto virtual, se é possível afirmar que houve mudanças também na percepção desses estudantes, uma vez que são estudantes nativos digitais.

\section{METODOLOGIA}

O estudo é direcionado para estudantes do ensino técnico pós-médio do Curso de Edificações. Até o momento, 32 estudantes de duas turmas de semestres distintos participaram da pesquisa, sendo 14 da turma de 2017/2 (estudo piloto) e 18 da turma de 2018/1. Os resultados apresentados neste trabalho se referem à aplicação da atividade com a segunda turma. Conforme contextualizado introdutoriamente, estes estudantes são nativos digitais. Têm idade média de 22 anos, sendo o mais novo de 18 anos e o mais velho de 30 anos.

A pesquisa tem se desenvolvido no âmbito da disciplina de Desenho Arquitetônico 1 (DA1), que recebe os estudantes ingressantes no curso, portanto, estudantes cujo conhecimento de geometria gráfica e sistemas projetivos é praticamente nulo, já que, conforme explicitado anteriormente, o atual ensino médio pouco contribui para a construção desses conhecimentos por parte dos estudantes. Essa carência de conhecimentos prévios advindos do ensino médio se confirma a partir da análise dos questionários, onde foi solicitado que os estudantes apontassem os conhecimentos que possuíam relacionados à atividade desenvolvida. Dos estudantes que revelaram ter algum conhecimento sobre desenho, apenas um estudante indicou ter estudado desenho geométrico durante o ensino médio. Os demais tiveram contato com estes conceitos em cursos de formação profissional (técnicos de nível médio ou cursos de nível superior).

Com relação aos conteúdos, a disciplina de DA1 envolve um momento inicial de introdução ao desenho técnico onde se faz necessária a explanação dos fundamentos da geometria descritiva através do sistema bi projetivo Mongeano, posições de pontos, retas, planos e suas projeções. Este momento introdutório subsidia atividades de reconhecimento, através do uso da cor, de diferentes posições de planos em desenhos de peças fornecidos em perspectiva isométrica e, também, exercícios de representação de vistas ortográficas a mão livre. Esta parte introdutória antecede o estudo das representações próprias do desenho arquitetônico, objetivo principal da disciplina. Com relação aos recursos, a disciplina atualmente preserva a representação manual com auxílio de instrumentos de desenho, com exceção de exercícios iniciais que empregam o uso de croquis a mão livre.
A revisão bibliográfica foi organizada a partir do interesse das autoras em investir no resgate de teorias de desenvolvimento cognitivo como aporte para a estruturação de futuras experiências de ensinoaprendizagem. Entende-se que, diante do contexto atual dos estudantes que são nativos digitais e a crescente evolução dos recursos gráfico-digitais, este resgate se faz necessário até porque o modo como os estudantes aprendem está mudando.

Dentre as teorias que se dispõem a explicitar como ocorre o desenvolvimento cognitivo, Piaget se aproxima da problemática aqui abordada pois este autor estudou a psicogenética do desenvolvimento da criança a partir das noções do espaço (Piaget \& Inhelder, 1993 ) (Piaget, 2007). Com abordagem construtivista, Piaget defende que a apropriação do conhecimento pela criança se estabelece em função da interação deste com o meio, em estádios que evoluem desde o período sensório-motor (que ocorre dos 0 aos 2 anos e é caracterizado pelo início das interações sociais), passando pelo pré-operatório (entre 2 e 7 anos aproximadamente), operatório concreto (entre 7 e 12 anos), até atingirem o estádio das operações formais (a partir dos 11-12 anos aproximadamente). Cada um desses períodos se caracteriza pela aquisição, pelo indivíduo, de habilidades que avançam gradualmente desde as operações mais simples com objetos concretos até os mais elevados níveis de abstração, que constituem o desenvolvimento do raciocínio lógico-matemático. Piaget considera que cada estádio é caracterizado por processos graduais de assimilação e acomodação, necessários ao desenvolvimento do estádio seguinte.

Assim busca-se, com base nestas referências, investir na experiência com o 'concreto', buscando reduzir a abstração de maneira que os estudantes possam operar com os conceitos e, gradualmente, avancem para níveis mais elevados de abstração, próprios aos processos de decodificação de imagens. Considerando que grande parte dos estudantes não atingiu o estádio das operações formais, em que "é capaz de raciocinar sobre simples hipóteses" (Taille, Dantas, \& Oliveira, 2016, p. 18), sem a necessidade de manipular objetos, a experiência constitui uma tentativa de resgate através das operações com o concreto. Seja o concreto proporcionado por interação com modelo físico ou através da interação com modelo tridimensional no espaço digital.

A atividade proposta para responder à pergunta da pesquisa foi, então, estruturada a partir de duas experiências didáticas: uma experiência de interação com modelo digital no espaço virtual; e outra experiência de interação com modelo físico, através do manuseio de maquetes produzidas com tecnologia de impressão 3D. Os modelos utilizados (Figura 1) consistem em três sólidos (típicos do ensino de desenho técnico), diferentes entre si, porém cujas formas apresentam níveis semelhantes de dificuldade na solução da atividade proposta.
3 


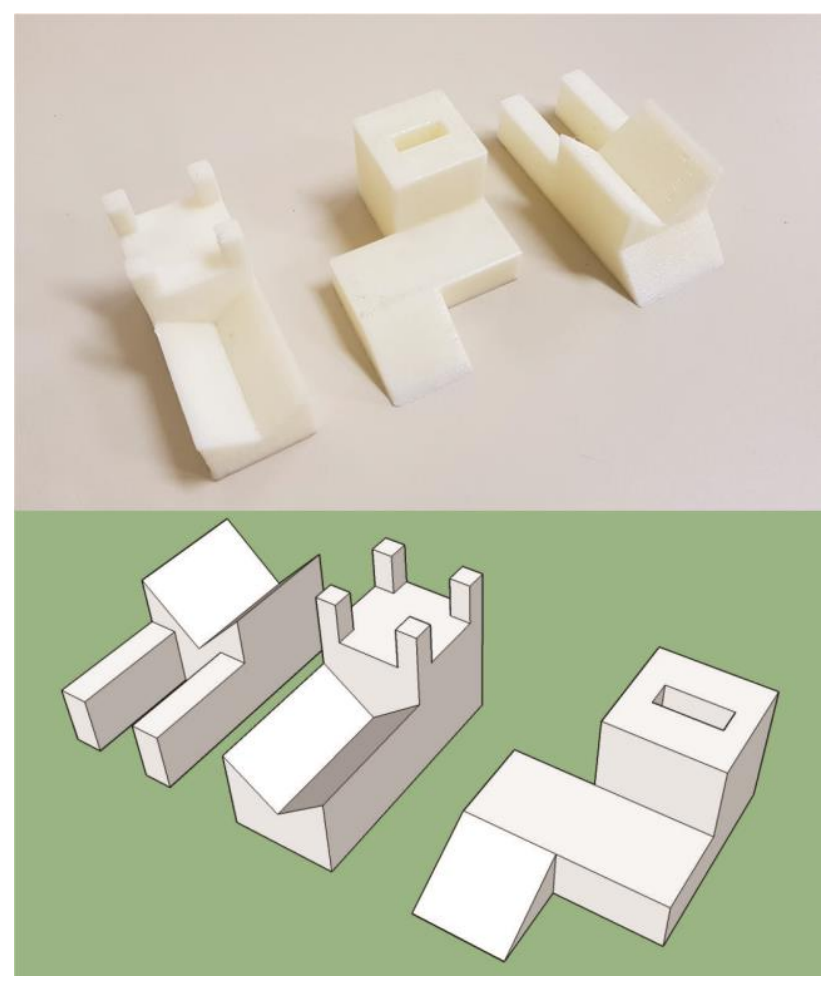

Figura 1: Modelos de sólidos criados a partir de impressão 3D (acima) e modelos digitais construídos com software Sketchup (abaixo). Fonte: autores.

A partir da primeira aplicação foram realizadas alterações, especialmente nos questionários aplicados para análise de percepção. Em ambas as experiências os estudantes realizaram inicialmente o exercício a partir da interação com o modelo digital. Entendeu-se, a partir do estudo piloto, a necessidade de realizar um questionário ao final de cada uma dessas experiências (física e digital), de forma que os estudantes registrassem suas percepções logo após cada atividade, com o objetivo de se obter respostas mais puras acerca de suas impressões sobre cada uma. Também foi aplicado um questionário final onde se questionou sobre a comparação entre as duas experiências e buscou-se investigar qual foi mais significativa ou mais auxiliou no desenvolvimento da atividade.

Os questionários aplicados são constituídos de perguntas fechadas e abertas. As perguntas fechadas correspondem a questões de múltipla escolha em escala de 5 pontos e as perguntas abertas, por sua vez, têm como objetivo obter outras categorias de respostas à pesquisa (Reis \& Lay, 1995). Os dados quantitativos, produtos dos questionários, foram analisados através de testes de frequência, assim como os qualitativos considerados quantificáveis. Segundo Reis e Lay (1995, p. 22), a análise qualitativa utiliza interpretações e julgamentos subjetivos ou, se quantificáveis, a análise pode ser complementada com a interpretação das frequências obtidas. Para associar as percepções dos estudantes ao resultado das atividades, também foram analisados os desenhos de vistas realizados. Estes exercícios foram corrigidos a partir da observação dos seguintes pontos: representação de arestas visíveis; representação de arestas ocultas; e correspondência entre vistas.

\section{RESULTADOS}

A análise do questionário respondido ao final da experiência revelou que, de modo geral os estudantes consideraram que, em conjunto, os diferentes meios de apresentação do objeto colaboraram para um melhor entendimento da peça: $75 \%$ consideraram que 'colaborou muito' e $25 \%$ consideraram que 'colaborou', portanto nenhum respondente considerou que as experiências foram 'neutras', 'pouco colaboraram' ou 'não colaboraram'.

Porém observou-se uma pequena diferença com relação ao quão interessante estes estudantes acharam cada um dos modelos: 91,7\% consideraram o modelo digital 'muito interessante' enquanto que a maioria dos respondentes indicou o modelo físico como 'interessante' 58,3\% (Figura 2). Embora haja a predominância de uma percepção positiva em ambas as experiências, o modelo digital é um pouco mais interessante na percepção dos estudantes.

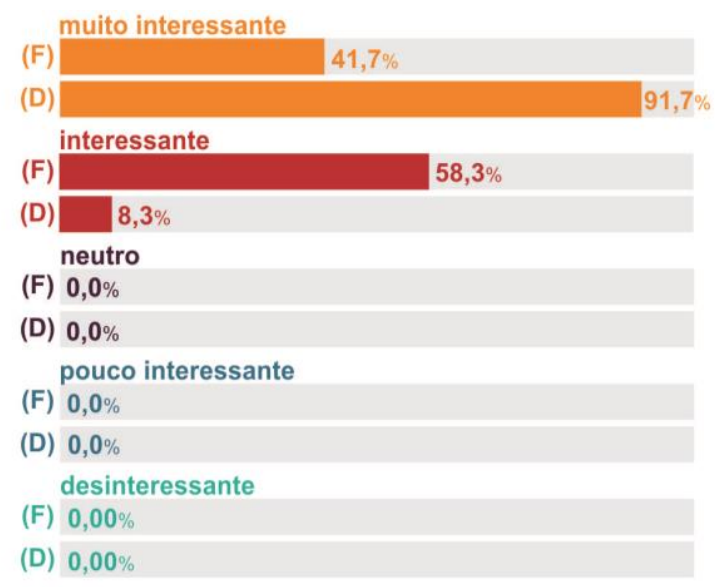

Figura 2: Percepção dos estudantes sobre o quão interessante entenderam os modelos físico (F) e digital (D). Fonte: autores.

Por outra parte, quando questionados sobre qual modelo (físico ou digital) melhor contribuiu para a atividade, observou-se uma clara preferência por parte dos estudantes pela experiência com o modelo digital: $83,3 \%$ deles consideraram que o modelo digital contribuiu mais para a clareza e compreensão da peça (Figura 3) enquanto que $16,7 \%$ apontaram para o modelo físico nesta questão. De modo semelhante, essa preferência se revela também em outra questão: $91,7 \%$ dos estudantes afirmaram que o modelo digital melhor auxiliou no desenvolvimento da atividade de desenho de vistas ortográficas contra apenas $8,3 \%$ que preferiram o modelo físico (Figura 4).

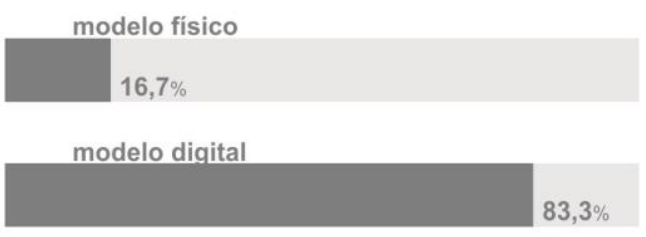


Figura 3: Percepção dos estudantes sobre qual modelo, físico ou digital, melhor contribui para a clareza e compreensão da peça. Fonte: autores.

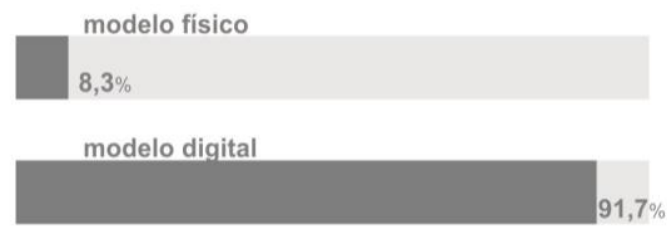

Figura 4: Percepção dos estudantes sobre qual modelo, físico (F) ou digital (D), melhor auxiliou o desenvolvimento da atividade de desenho de vistas ortográficas. Fonte: autores.

O interesse pela tecnologia digital também se revelou quando $92 \%$ consideraram o ambiente computacional, (D), 'muito interessante' e $8 \%$ consideraram 'interessante', sendo que nenhum estudante considerou 0 ambiente computacional 'neutro', 'pouco interessante' ou 'desinteressante'. Já o desenho a mão com instrumentos (F) foi considerado por $67 \%$ dos respondentes como 'muito interessante', 25\% consideraram 'interessante', 8\% consideraram 'neutro' e, portanto, nenhum estudante considerou o desenho a mão 'pouco interessante' ou 'desinteressante' (Figura 1Figura 5).

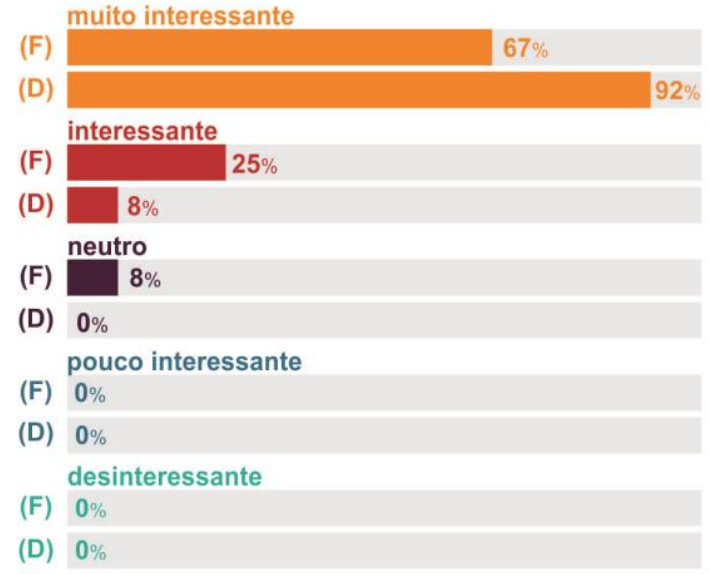

Figura 5: Percepção dos estudantes sobre 0 ambiente computacional e o desenho à mão. Fonte: autores.

A aparente preferência dos estudantes pela tecnologia digital também se verifica através das perguntas abertas, cujas respostas foram agrupadas por similaridade. Quando questionados sobre os motivos pelos quais entenderam que um ou outro modelo melhor contribuiu para a compreensão da peça, a razão mais indicada foi a 'facilidade de obter as medidas' no modelo digital. Por outro lado, a 'maior dificuldade em ter certeza das medidas' também foi indicada como o motivo pelo qual os estudantes entenderam que o modelo físico 'menos facilitou' a compreensão do objeto.

Isso também se verificou quando os estudantes informaram sobre suas percepções logo após a realização das experiências. Apenas $54,5 \%$ dos participantes afirmaram que a ferramenta de medição escalímetro 'facilitou muito' na compreensão das dimensões do objeto, enquanto que, com software Sketchup essa percepção foi de $83,3 \%$ ( Figura 6).
Entende-se que isto ocorre porque os nativos digitais são mais habituados à interação com ambientes virtuais. Por outro lado, eles demonstram dificuldade em realizar a leitura da medida com escalímetro porque o instrumento não fornece o resultado, tampouco a segurança de precisão pois ele precisa ser interpretado.

\begin{tabular}{|c|c|c|}
\hline (F) & & $54,5 \%$ \\
\hline (D) & & $83,3 \%$ \\
\hline & facilitou & \\
\hline (F) & $36,4 \%$ & \\
\hline (D) & $11,1 \%$ & \\
\hline & neutro & \\
\hline (F) & $9,1 \%$ & \\
\hline (D) & $5,6 \%$ & \\
\hline & $\overline{\text { pouco facilitou }}$ & \\
\hline (F) & $0,0 \%$ & \\
\hline (D) & $0,0 \%$ & \\
\hline & não facilitou & \\
\hline (F) & $0,00 \%$ & \\
\hline (D) & $0,00 \%$ & \\
\hline
\end{tabular}

Figura 6: Percepção dos estudantes sobre 0 uso das ferramentas de medição no espaço físico $(F)$ e no espaço digital (D). Fonte: autores.

Sobrepõem-se a estes resultados da percepção dos estudantes, os dados obtidos a partir da correção das atividades por parte das professoras, que não corrobora integralmente as percepções destes. Embora a clara preferência pelo modelo digital, observou-se que o nível de erros foi menor com o modelo físico ( Figura 7).

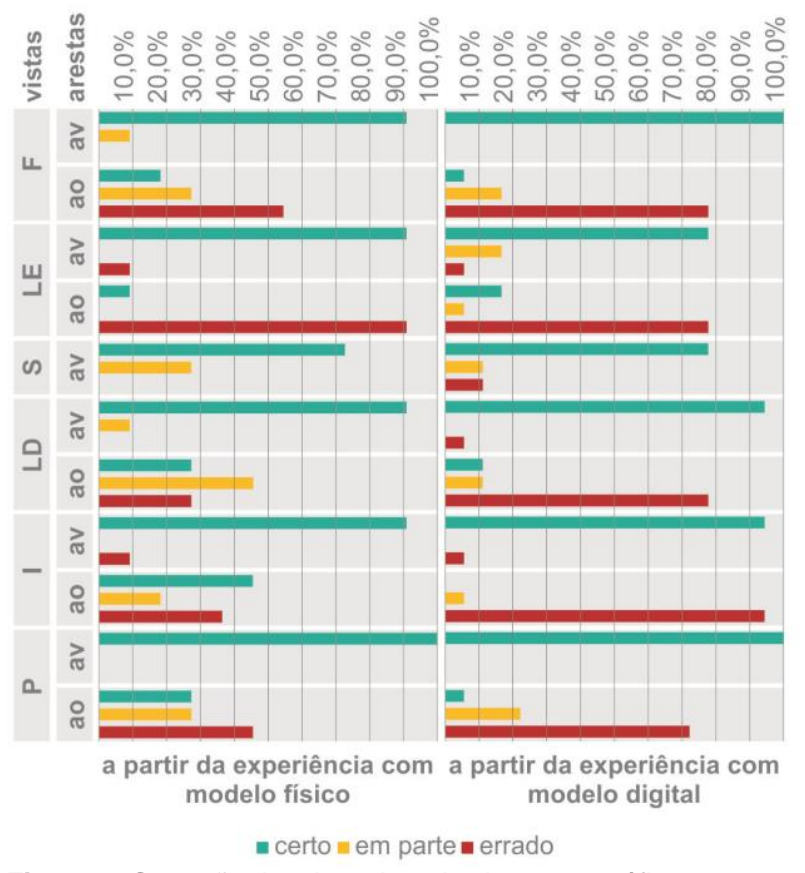

Figura 7: Correção dos desenhos de vistas ortográficas: arestas visíveis (av) e arestas ocultas (ao). Fonte: autores.

Destaca-se que, em ambos modelos, a representação de arestas ocultas foi a que apresentou a maior quantidade de erros, indicando a maior dificuldade dos estudantes, porém o modelo digital não parece ter contribuído para mitigar essa dificuldade. 
Da mesma forma, no modelo digital também foram identificados mais equívocos na correspondência entre as vistas (posição relativa e alinhamento) ( Figura 8).

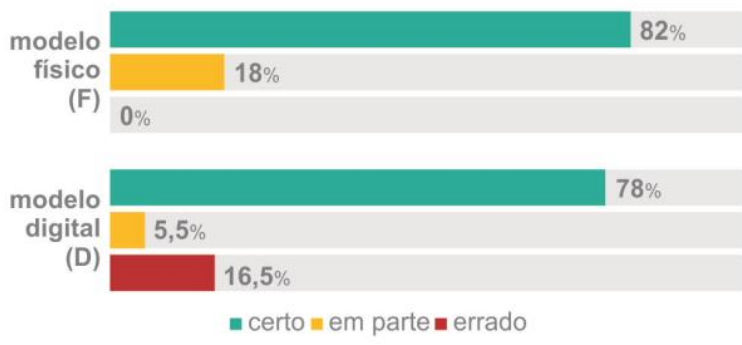

Figura 8: Correção dos desenhos de vistas ortográficas: correspondência entre as vistas. Fonte: autores.

Entende-se com isto que, no entendimento de qual vista ortográfica se está representando e como esta deve ser posicionada em relação às demais, o manuseio da peça pode ter sido mais significativo. No ambiente digital, sem esse conhecimento sistematizado, a ferramenta 'exibições' que o software oferece permite a visualização das vistas ortográficas, porém sem explicitar a correspondência entre elas a partir da escolha da vista frontal.

\section{DISCUSSÃO}

A partir dos resultados parciais, entende-se que a preferência pelo emprego das tecnologias gráfico-digitais contribui para a motivação dos estudantes no desenvolvimento das atividades, o que pode influenciar para uma aprendizagem mais efetiva.

Por outro lado, a diferença entre o nível de erros a partir do exercício com cada um dos modelos, indica que o modelo físico, embora menos cativante, aparentemente contribuiu mais para a compreensão da peça, ainda que os estudantes não tenham essa percepção. Mesmo que a atividade com o modelo físico tenha sido realizada após a atividade com o modelo digital, portanto com certa vantagem em relação ao primeiro, entende-se que os estudantes ainda não teriam se apropriado inteiramente dos conceitos apresentados na aula teórica. Além disso, realizaram a atividade com outro objeto e não tinham recebido retorno da correção da primeira atividade até aquele momento. Mesmo assim, aponta-se para a importância de inverter a ordem das experiências em aplicações futuras, de forma a verificar o quão significante a questão da ordem das experiências pode ser.

Apesar da ferramenta SketchUp ser desconhecida da maior parte dos estudantes, isso não se configurou como um problema. Estudantes que são "nativos digitais" têm facilidade em explorar essas ferramentas, o que se revela nos motivos descritos pela preferência ao modelo digital e corrobora a análise de Prenski a respeito do perfil deles. Uma das hipóteses que as autoras discutem é que, para estes estudantes, a experiência com o modelo digital pode ser quase tão concreta quanto a experiência com o modelo físico. Considerando a avaliação dos estudantes de que ambas experiências auxiliaram na compreensão dos objetos, admite-se que sua manipulação, tanto em meio físico quanto digital, é importante para o desenvolvimento do raciocínio visuoespacial. Assim, a teoria de Piaget se mostrou adequada à compreensão do problema desta pesquisa. Através da descrição dos estádios, ilustra como o desenvolvimento idealmente deveria ocorrer, de forma lenta e sequencial. Fornece subsídios para compreender estes estádios e os processos de desenvolvimento cognitivo, e de como a interação pode ser relevante para estes processos porque permite que o estudante opere com conceitos antes de abstraí-los. Assim, acredita-se que as atividades didáticas podem e devem incluir experiências sobre o concreto como meio de facilitar o avanço a raciocínios lógico-matemáticos mais abstratos.

Uma leitura geral que se faz dos resultados apresentados é que os recursos digitais e físicos devem ser explorados a partir de suas potencialidades, complementando-se. Novos exercícios, independentemente da tecnologia adotada, devem incorporar características que desafiem e instiguem a curiosidade dos estudantes. A similaridade com os jogos eletrônicos aproxima a prática didática do universo dos nativos digitais, estimulando sua aprendizagem através de atividades que fazem relação entre seus interesses e forma de pensar. No entanto, conforme a reflexão de Flusser, os professores devem fazer uso das tecnologias buscando suplantar a "caixa negra", utilizando-as como meio de solucionar problemas e estimulando os estudantes a fazerem o mesmo. Espera-se, a partir destas reflexões, contribuir para a prática didática de representação gráfica apoiada em atividades voltadas para o desenvolvimento do raciocínio visuoespacial na formação profissional da área da construção civil.

\section{REFERÊNCIAS}

Bueno, M. S. (2015). Quem, afinal, nas escolas brasileiras, promove o desenvolvimento das competências gráficas? III APROGED'S International Conference [e] XVI International Conference on Graphics Engineering for Arts and Design. 1, pp. 477-487. Porto: APROGED.

Carr, N. (2011). The Shallows: What the Internet Is Doing to Our Brains. . New York, London: W. W. Norton \& Company.

Castral, P. C. (2014). O desenhar do Arquiteto: Um estudo sobre a utilização do desenho a mão livre como forma de investigação. São Carlos: Instituto de Arquitetura e Urbanismo de São Carlos IAU - USP.

Florio, W. (janeiro de 2013). O croqui no Atelier de Projeto Desafios no ensino de Arquitetura na Era Digital. Revista Brasileira de Expressão Gráfica, 1, 50-76.

Flusser, V. (1998). Ensaio sobre a fotografia- para uma filosofia da técnica. Lisboa: Relógio D’Água Editores.

Kopke, R. C. (2009). Objetos esculpidos e a visão espacial. VIII International Conference on Graphics Engineering for Arts and Design e XIX Simpósio Nacional de Geometria Descritiva e Desenho Técnico. (pp. 869-881). Bauru: UNESP.

Piaget, J. (2007). Epistemologia genética. São Paulo: Martins Fontes.

Piaget, J., \& Inhelder, B. (1993 ). A representação do espaço na criança. Porto Alegre: Artes Médicas.

Prenski, M. (October de 2001). Digital Natives, Digital Immigrants - Part 1. On the Horizon, 1-6.

Reis, A., \& Lay, M. (1995). As técnicas de APO como Instrumento de Análise Ergonômica do Ambiente Construído. III Encontro Nacional e I Encontro Latino-Americano de Conforto no Ambiente Construído. (p. 31p.). Gramado: ANTAC - Associação Nacional de Tecnologia do Ambiente Construído.

Rheingantz, P. A. (jan-jun de 2016). Projeto de Arquitetura: processo analógico ou digital? Gestão e Tecnologia de Projetos, 11, 95-102.

Sennet, R. (2015). O artífice. Rio de Janeiro: Record. 
Taille, I. d., Dantas, H., \& Oliveira, M. K. (2016). Piaget, Vygotsky, Wallon: teorias psicogenéticas em discussão. São
Paulo: Summus. 